\title{
Are Truelove and Witts criteria for diagnosing acute severe colitis relevant for the Indian population? A prospective study
}

\author{
Saransh Jain ${ }^{1}$, Saurabh Kedia ${ }^{1}$, Sawan Bopanna ${ }^{1}$, Dawesh P Yadav ${ }^{1}$, Sandeep Goyal ${ }^{1}$, Peush Sahni ${ }^{2}$, \\ Sujoy Pal ${ }^{2}$, Nihar Ranjan Dash ${ }^{2}$, Govind Makharia ${ }^{1}$, Simon P. L. Travis ${ }^{3}$, Vineet Ahuja ${ }^{1}$ \\ Departments of ${ }^{1}$ Gastroenterology and ${ }^{2}$ Gastrointestinal Surgery, All India Institute of Medical Sciences, New Delhi, India, ${ }^{3}$ Translational \\ Gastroenterology Unit, Oxford University Hospitals, Oxford, UK
}

Background/Aims: Truelove and Witts criteria have been used to define acute severe colitis since the 1950s. However, hemoglobin (an additional criterion of the definition) levels in the general population in developing countries are lower than in the population of developed countries. We aimed to determine the relevance of Truelove and Witts criteria in the Indian population. Methods: Consecutive patients with acute severe colitis satisfying the Truelove and Witts criteria, hospitalized at a single center between April 2015 and December 2016 were included. All patients received intravenous corticosteroids and 16 required colectomy. The hemoglobin levels at admission were subsequently excluded from the classification criteria, and the effect this had on the criteria for diagnosis was determined. Results: Out of 61 patients of acute severe colitis diagnosed according to the original Truelove and Witts criteria, 12 patients (20\%) had 1 additional criterion, 33 (54\%) had 2 additional criteria and $16(26 \%)$ had 3 or more additional criteria in addition to 6 or more blood stained stools on admission. On excluding hemoglobin as an additional criterion from the Truelove and Witts definition, all patients still met the criteria for acute severe colitis. Conclusions: Truelove and Witts criteria can be used to define acute severe colitis in India, despite lower mean hemoglobin in the native population. (Intest Res 2018;16:69-74)

Key Words: Acute severe colitis; Definition; Anemia; Truelove and Witts criteria; India

\section{INTRODUCTION}

The burden of IBD in India and other Asian countries has increased in recent times, and the projected IBD population in India is second highest in the world after the United States. ${ }^{1-3}$ UC has a relapsing and remitting course, and acute severe colitis (ASC) complicates the course of UC in up to $25 \%$ of cases, with a third of these episodes being the first presentation of UC. ${ }^{4,5}$ The course of UC is similar between the West and Asia, and in an earlier prospective study, we

Received July 21, 2017. Revised August 26, 2017.

Accepted August 29, 2017. Published online November 27, 2017

Correspondence to Vineet Ahuja, Department of Gastroenterology, All India

Institute of Medical Sciences, Room No. 3093, 3rd Floor, Teaching Block,

New Delhi 110029, India. Tel: +91-11-26593300, Fax: +91-11-2658663,

E-mail: vineet.aiims@gmail.com found similar short-term colectomy rates and response to intravenous (IV) steroids in 49 episodes of ASC. ${ }^{6}$ Truelove and Witts criteria ${ }^{7}$ are most widely used to define ASC. ${ }^{8-11}$ The definition is based on 6 or more blood stained stools daily, with 1 or more of the 4 additional criteria: hemoglobin $<105$ $\mathrm{g} / \mathrm{L}, \mathrm{ESR}>30 \mathrm{~mm} / \mathrm{h}$, fever $>37.8^{\circ} \mathrm{C}$, and tachycardia $>90 / \mathrm{min}$. Hemoglobin is 1 of the 4 relative criteria for the diagnosis of ASC. Nevertheless, the hemoglobin cutoff of $105 \mathrm{~g} / \mathrm{L}$ is based on the normal levels of $130 \mathrm{~g} / \mathrm{L}$ in men and $120 \mathrm{~g} / \mathrm{L}$ in nonpregnant women, in the Western countires. ${ }^{12}$ In developing countries, the average hemoglobin in the population is lower, with normal being considered as $125 \mathrm{~g} / \mathrm{L}$ in men and $110 \mathrm{~g} / \mathrm{L}$ in nonpregnant women (Vietnam National Institute of Health study ${ }^{13}$ ) or $123 \mathrm{~g} / \mathrm{L}$ and $110 \mathrm{~g} / \mathrm{L}$ respectively, in a study from India. ${ }^{14}$ A lower hemoglobin in our country could

\footnotetext{
๑ Copyright 2018. Korean Association for the Study of Intestinal Diseases. All rights reserved.

This is an Open Access article distributed under the terms of the Creative Commons Attribution Non-Commercial License (http://creativecommons.org/licenses/by-nc/4.0)

which permits unrestricted non-commercial use, distribution, and reproduction in any medium, provided the original work is properly cited.
} 
lead to over-diagnosis of ASC if conventional Truelove and Witts criteria are applied, with needless hospitalization and increased cost or unnecessary IV corticosteroids.

This study was therefore planned to evaluate the relevance of Truelove and Witts criteria for diagnosing ASC in India.

\section{METHODS}

We diagnosed ASC using the conventional Truelove and Witts criteria and then assessed the effect on the rate of diagnosis of ASC, by excluding patients in whom the only positive additional criterion was hemoglobin $<105 \mathrm{~g} / \mathrm{L}$. All consecutive patients diagnosed with ASC based on Truelove and Witts criteria who were hospitalized at All India Institute of Medical Sciences (AIIMS), New Delhi, India from April 2015 to December 2016 were screened for inclusion. Written informed consent was obtained from all patients. Children $<18$ years and patients refusing to give consent were excluded (ethical approval AIIMS IRB number: IESC/T-277).

\section{Definitions}

UC: diagnosis based on clinical, radiological, and histological criteria. ${ }^{15}$ Patients with first presentation of disease with ASC who were later found to be suffering from an infection or Crohn's colitis were excluded.

ASC: based on Truelove and Witts criteria; 6 or more stools with blood and 1 or more of hemoglobin $<105 \mathrm{~g} / \mathrm{L}$, ESR $>30 \mathrm{~mm} / \mathrm{h}$, fever $>37.8^{\circ} \mathrm{C}$, or tachycardia $>90 / \mathrm{min}^{7.8}$

Disease extent: maximum macroscopic extent on colonoscopy preceding ASC, according to the Montreal classification. ${ }^{16}$ For patients presenting with ASC at diagnosis, the extent was determined using the first colonoscopy after discharge or the surgical specimen if they underwent colectomy.

Prior steroid use: any use of systemic corticosteroids prior to the index episode of ASC. Steroid use in the first year of diagnosis: corticosteroids usage in the first year after diagnosis, including the ASC event if it occurred within the first year of diagnosis.

Ulcerative colitis endoscopic index of severity (UCEIS): ${ }^{17}$ the sum of 3 descriptors: vascular pattern (score, $0-2$ ); bleeding (score, $0-3$ ); and erosions and ulcers (score, $0-3$ ), range from 0 to 8 , assessed in the most severely affected area on flexible sigmoidoscopy (S.J.).

\section{Study Design}

This was a prospective, observational cohort study. Data on baseline demographics, prior therapy for UC, plain ab- dominal radiograph and endoscopic assessment of severity (UCEIS $)^{17}$ using unprepared flexible sigmoidoscopy within 24 hours of admission, clinical observations of pulse rate, temperature, blood pressure, stool frequency, and laboratory parameters during the hospital stay were included. Serum CRP was performed on day 3 of IV corticosteroid therapy and Clostridium difficile toxin assay was performed using ELISA, for both toxins A and B. Subsequently the patients diagnosed with ASC were reclassified after excluding hemoglobin as one of the diagnostic criteria, to evaluate the confounding effect of baseline hemoglobin on ASC diagnosis.

\section{Management}

All patients received IV and rectal hydrocortisone (400 $\mathrm{mg} /$ day IV, $200 \mathrm{mg}$ /day per rectum), whilst continuing 5 -aminosalicylic acid therapy, according to the guidelines, ${ }^{18}$ as well as antibiotics (ciprofloxacin and metronidazole), given the prevalence of gastrointestinal infection in India. Blood transfusion was given as required (hemoglobin $<80 \mathrm{~g} / \mathrm{L}$ ), mucosal biopsies were taken during flexible sigmoidoscopy to exclude cytomegalovirus (CMV) infection. Oxford criteria ${ }^{19}$ were used to identify patients at high risk of colectomy and if unresponsive to 5 to 7 days of IV corticosteroids, rescue therapy or colectomy was advised. The choice, decision, and timing of colectomy was arrived at after a joint medicalsurgical review and patient counselling. Patients responding to IV corticosteroids were discharged on $40 \mathrm{mg} /$ day prednisolone with a tapering period of 3 to 4 months, along with azathioprine.

\section{Statistical Analysis}

Continuous variables were expressed as the mean $\pm S D$ and those with non-Gaussian distribution as median and range. Categorical variables were summarized as frequencies with percentages rounded up or down to the nearest integer. Analyses were performed using SPSS software version 24.0 (IBM Corp., Armonk, NY, USA).

\section{RESULTS}

\section{Patients}

In all, 59 patients with 63 episodes of ASC were hospitalized during the study period, of which 2 patients were excluded (Fig. 1). Thus, 57 patients with 61 episodes of ASC were included in the study. Response to IV corticosteroids was seen in 38 of 61 episodes and 23 of 61 did not respond. 


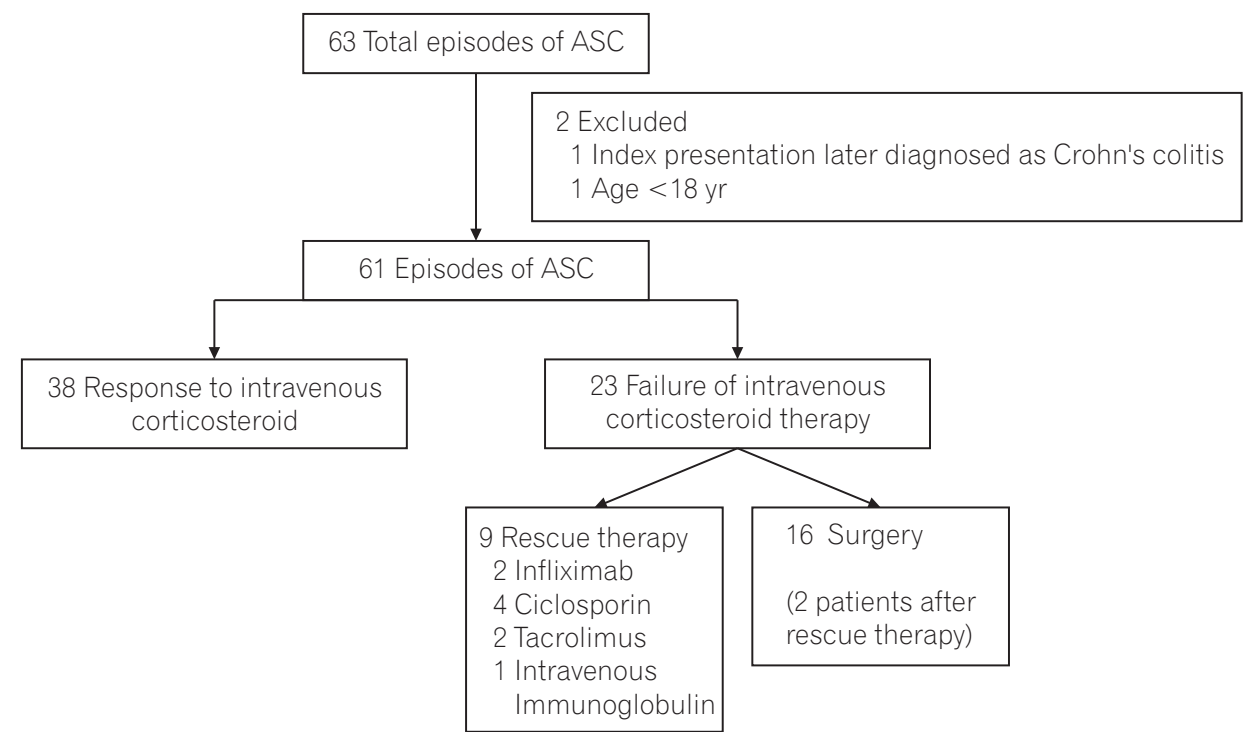

Fig. 1. Standard acronym diagram: study population. ASC, acute severe colitis.
Of these, 9 of 23 received rescue therapy ( 4 ciclosporin, 2 tacrolimus, 2 infliximab, and 1 patient received IV Immunoglobulin). ${ }^{20,21}$ Sixteen of 23 patients underwent surgery, including 2 after rescue therapy.

\section{Baseline Demographic and Clinical Characteristics}

Mean age on admission was $36 \pm 13$ years, $69 \%$ were men. Median duration of UC prior to diagnosis was 36 months and 7\% presented with ASC at diagnosis. Two-thirds had extensive colitis and one-third had extraintestinal manifestations. One-third had history of a previous episode of ASC and $57 \%$ had used steroids in the first year of diagnosis, whereas $80 \%$ had used steroids at some stage after diagnosis (Table 1).

\section{Clinical and Laboratory Parameters during Hospitalization}

Median stool frequency on the day of presentation was 12 (range, 6-23), which decreased to 6 (range, 2-18) on day 3 of IV corticosteroids (Table 1). Median hemoglobin was 97 $\mathrm{g} / \mathrm{L}$ (range, 47-155 g/L), ESR on admission was $42 \mathrm{~mm} / \mathrm{h}$ (range, $10-82 \mathrm{~mm} / \mathrm{h}$ ) and $25 \%$ received blood transfusion(s) (Table 2, Fig. 2). Median CRP on day 1 was $59 \mathrm{mg} / \mathrm{L}$ (range, 4-205 mg/L). Median UCEIS was 5 (range, 4-8) and median CRP level on day 3 of IV corticosteroid was $16 \mathrm{mg} / \mathrm{L}$ (range, 1-209 mg/L). One patient was positive for $C$. difficile toxin in stool and cytomegalovirus immunohistochemistry was positive in 10 of 61 episodes (16\%). Patients received IV cor-
Table 1. Baseline Demographic and Clinical Characteristics of Our Cohort $(n=61)$

\begin{tabular}{lc}
\hline \multicolumn{1}{c}{ Variable } & Value \\
\hline Age (yr) & $36 \pm 13$ \\
Duration of UC prior to ASC (mo) & $36(1-180)$ \\
\hline Male sex & $42(69)$ \\
\hline Index presentation of UC as ASC & $4(7)$ \\
\hline Extent & \\
\hline E2 (left sided colitis) & $20(34)$ \\
\hline E3 (extensive colitis) & $39(66)$ \\
\hline Prior azathioprine & $28(46)$ \\
\hline Previous ASC & $18(30)$ \\
\hline Prior steroid use & $49(80)$ \\
\hline Steroid use in 1st yr of diagnosis of UC & $35(57)$ \\
\hline Tobacco user & $11(18)$ \\
\hline Presence of EIMs & $18(30)$ \\
\hline Pulse rate on admission (/min) & $100(69-142)$ \\
\hline Stool frequency on admission (/day) & $12(6-23)$ \\
\hline Pulse rate beginning day 3 (/min) & $84(60-110)$ \\
\hline Stool frequency during day 3 (/day) & $6(2-18)$ \\
\hline
\end{tabular}

Value are presented as mean $\pm S D$, median (range), or number (\%). aExtent was not available in 2 patients.

ASC, acute severe colitis; EIMs, extraintestinal manifestations.

ticosteroids for a median 5 days (range, $3-10$ days) with the duration of hospital stay being 10 days (range, 5-36 days). Four patients developed toxic megacolon, all of whom underwent colectomy. One patient died on postoperative day 3 from ventricular arrhythmia because of hypokalemia. 
Table 2. Comparison of Laboratory Parameters and Management among Patients with Acute Severe Colitis ( $n=61)$

\begin{tabular}{|c|c|}
\hline Variable & Value \\
\hline Hemoglobin on admission (g/L) & $97(47-155)$ \\
\hline ESR on admission $(\mathrm{mm} / \mathrm{h})$ & $42(10-82)$ \\
\hline CRP at admission $(\mathrm{mg} / \mathrm{L})^{\mathrm{a}}$ & $59(4-205)$ \\
\hline Blood transfusion & $15(25)$ \\
\hline White cell count $\left(\times 10^{9} / \mathrm{L}\right)$ & $8.6(1.4-30.7)$ \\
\hline Platelet day on admission $\left(\times 10^{9} / \mathrm{L}\right)$ & $352(51-764)$ \\
\hline Albumin on admission (g/L) & $30(10-46)$ \\
\hline UCEIS on admission & $5(4-8)$ \\
\hline Hemoglobin day 3 (g/L) & $95(61-144)$ \\
\hline Platelet day $3\left(\times 10^{9} / \mathrm{L}\right)$ & $317(91-622)$ \\
\hline CRP day 3 (mg/L) & $16(1-209)$ \\
\hline Albumin day 3 (g/L) & $30(11-46)$ \\
\hline Meeting Oxford 3rd day criteria ${ }^{b}$ & $26(43)$ \\
\hline Stool positive for Clostridium difficile toxin & $1(2)$ \\
\hline Toxic megacolon during admission & $4(7)$ \\
\hline Duration of IV steroid (day) & $5(3-10)$ \\
\hline Duration of admission (day) & $10(5-36)$ \\
\hline Mortality & $1(2)$ \\
\hline
\end{tabular}

Values are presented as median (range) or number (\%). Extent was not available in 2 patients.

${ }^{a} \mathrm{CRP}$ at admission was not available in 7 patients.

${ }^{6}$ Oxford 3rd day criteria: stool frequency $>8 /$ day or CRP $>45 \mathrm{mg} / \mathrm{L}$ and 3 to 8 stools on 3rd day of intravenous (IV) corticosteroid therapy. UCEIS, ulcerative colitis endoscopic severity index.

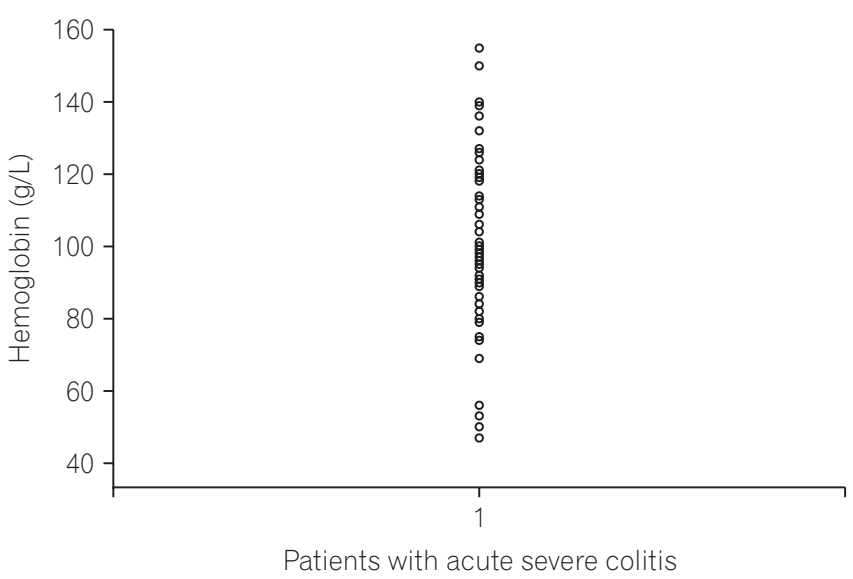

Fig. 2. Dot-plot showing distribution of hemoglobin values in our patient cohort.

\section{Truelove and Witts Criteria at Admission}

\section{1) All Criteria}

All patients had $\geq 6$ blood stained stools/day at admission. Twelve patients (20\%) had 1 additional criterion, 33 (54\%) had 2 additional criteria, and $16(26 \%)$ had 3 or more additional criteria on admission (Table 3). The most common additional criterion was tachycardia (pulse rate $>90 / \mathrm{min}$ ) seen in 48 of 61 episodes (79\%), followed by hemoglobin $<105 \mathrm{~g} / \mathrm{L}$ in 40 (66\%), ESR $>30 \mathrm{~mm} / \mathrm{h}$ in 37 (61\%), whereas fever was least common, seen in only 3 of episodes (5\%) (Table 4). CRP on admission $>30 \mathrm{mg} / \mathrm{L}$ was seen in 39 episodes (64\%). Among patients who had only 1 additional criterion $(\mathrm{n}=12)$ the most common criterion was tachycardia $(\mathrm{n}=10)$, followed by ESR $>30 \mathrm{~mm} / \mathrm{h}(\mathrm{n}=2)$. None of the patients had hemoglobin as the only additional criterion.

\section{2) Excluding Hemoglobin}

On excluding hemoglobin as an additional criterion, all patients still classified as ASC, but now with 37 of 61 (61\%) having only 1 additional criterion and 24 (39\%) having 2 or 3 additional criteria on admission (Table 5 ).

\section{DISCUSSION}

In this prospective cohort study of 61 consecutive episodes of ASC in 59 patients, we found that $80 \%$ of the episodes were associated with 2 or more additional Truelove and Witts criteria on admission, of which the commonest were tachycardia and low hemoglobin. The median hemoglobin on admission was $97 \mathrm{~g} / \mathrm{L}$ (range, $47-155 \mathrm{~g} / \mathrm{L}$ ), which is lower than that seen in Western studies. ${ }^{19,22,23}$ However, only $20 \%$ of the episodes were associated with a single additional Truelove and Witts criterion, of which none had hemoglobin $<105$ $\mathrm{g} / \mathrm{L}$ as the only additional criterion. This was lower than the rate of $40 \%$ reported in previous studies. ${ }^{424}$ Even among Indian women, who have lower mean hemoglobin levels, with minimum population thresholds reported as 113, 110, and $100 \mathrm{~g} / \mathrm{L}$ in studies by Ashavaid et al., ${ }^{14}$ NIN criteria $^{13}$ and Pasupula and Reddy, ${ }^{25}$ none of the episodes had hemoglobin as the only additional criterion for diagnosis of ASC. Therefore, after excluding hemoglobin as an additional criterion based on the original Truelove and Witts definition, all episodes still classified as ASC. Conceptually, ASC presents when the inflammatory activity of UC causes systemic manifestations of inflammation. This may explain why there appears to be no confounding effect of excluding hemoglobin on the diagnosis of ASC, despite a lower mean hemoglobin in the Indian population. It needs to be mentioned that Truelove and Witts criteria have never been subject to a mathematical 
Table 3. Truelove and Witts Criterion at Admission in Our Cohort

\begin{tabular}{cc}
\hline $\begin{array}{c}\text { No. of conventional Truelove and } \\
\text { Witts criteria on admission in addition to } \\
\text { blood stained stool frequency } \geq \mathbf{6}\end{array}$ & No. (\%) \\
\hline 1 & $12(20)$ \\
2 & $33(54)$ \\
3 & $15(24)$ \\
4 & $1(2)$ \\
\hline
\end{tabular}

Table 4. Individual Additional Criteria in Truelove and Witts and Their Frequency in Our Cohort

\begin{tabular}{cc}
\hline Individual criteria & No. (\%) \\
\hline Hemoglobin $<105 \mathrm{~g} / \mathrm{L}$ & $40(66)$ \\
Temperature $>37.8^{\circ} \mathrm{C}$ & $3(5)$ \\
$E S R>30 \mathrm{~mm} / \mathrm{h}$ & $37(61)$ \\
Pulse rate $>90 /$ min & $48(79)$ \\
\hline
\end{tabular}

Table 5. Comparison of Truelove and Witts Criteria with and without Hemoglobin as Additional Criterion to Diagnose Acute Severe Colitis $(n=61)$

\begin{tabular}{lcc}
\hline & $\begin{array}{c}\text { Conventional } \\
\text { Truelove and } \\
\text { Witts criteria }\end{array}$ & $\begin{array}{c}\text { Truelove and Witts } \\
\text { criteria excluding } \\
\text { hemoglobin }\end{array}$ \\
\hline No. of additional criteria satisfied \\
1 & 12 & 37 \\
2 & 33 & 22 \\
3 & 15 & 2 \\
4 & 1 & NA \\
\hline
\end{tabular}

NA, not applicable.

analysis of the contribution of components to the diagnostic value of the index, which would be standard practice in the development of indices today ${ }^{26}$ Patients with ASC have other signs of systemic inflammation that are manifest along with low hemoglobin, thereby maintaining the relevance of Truelove and Witts criteria other than hemoglobin, in this setting.

Both ESR and pulse rate increase with anemia, and this may further question the validity of Truelove and Witts criteria in the Indian setting, with an elevated ESR or tachycardia being a feature of anemia rather than systemic inflammation. However, patients identified with ASC in the present study had a short-term colectomy rate of $26 \%$ and steroid failure rate of $38 \%$, which are very similar to reports from the West. ${ }^{4}$ Using CRP $>30 \mathrm{mg} / \mathrm{L}$ instead of an ESR $>30 \mathrm{~mm} /$ $\mathrm{h}$ would have strengthened our conclusions, since CRP is independent of anemia, and 39 of 61 patients (64\%) had CRP $>30 \mathrm{mg} / \mathrm{L}$ on admission. Although 8 of 39 patients with an elevated CRP had normal ESR, all had at least 1 other Truelove and Witts criterion for the diagnosis of ASC.

The limitations of this study include referral bias owing to the tertiary nature of our institution and the lack of data about outpatients with an acute flare up of colitis and hemoglobin $<105 \mathrm{~g} / \mathrm{L}$. According to the protocol at AIIMS, patients with blood stained stool frequency $>6$ /day and hemoglobin $<105 \mathrm{~g} / \mathrm{L}$ merit admission, but it cannot be confirmed that clinicians did not make an allowance for lower hemoglobin in the Indian population and treated them as outpatients. Whilst this may explain the absence of any patient with a low hemoglobin as the only additional criterion, it also indicates that they can be managed as outpatients. These results also need validation in other centers.

We conclude that Truelove and Witts criteria are relevant in the Indian settings, which is reassuring given the lower mean hemoglobin in the general population.

\section{FINANCIAL SUPPORT}

The authors received no financial support for the research, authorship, and/or publication of this article.

\section{CONFLICT OF INTEREST}

No potential conflict of interest relevant to this article was reported.

\section{AUTHOR CONTRIBUTION}

S.J., study design, acquisition of data, analysis, and interpretation of data, drafting the manuscript, critical revision, and final approval of the manuscript; S.K., S.B., D.P.Y., S.G., analysis and interpretation of data, drafting the manuscript, critical revision, and final approval of the manuscript; P.S., S.P., N.R.D., G.M., S.P.L.T., drafting the manuscript, critical revision and final approval of the manuscript; V.A., study concept and design, analysis and interpretation of data; study supervision, drafting of the manuscript, critical revision, and final approval of the manuscript.

\section{ACKNOWLEDGEMENTS}

We are particularly grateful to our patients, colleagues, nursing, pharmacy, clerical staff, and allied professionals 
who collectively support our IBD services and enable studies such as this to be performed.

\section{REFERENCES}

1. Singh P, Ananthakrishnan A, Ahuja V. Pivot to Asia: inflammatory bowel disease burden. Intest Res 2017;15:138-141.

2. Kedia S, Ahuja V. Epidemiology of inflammatory bowel disease in India: the Great Shift East [published online ahead of print April 18, 2017]. Inflamm Intest Dis. doi: 10.1159/000465522.

3. Ng WK, Wong SH, Ng SC. Changing epidemiological trends of inflammatory bowel disease in Asia. Intest Res 2016;14:111119.

4. Dinesen LC, Walsh AJ, Protic MN, et al. The pattern and outcome of acute severe colitis. J Crohns Colitis 2010;4:431-437.

5. Edwards FC, Truelove SC. The course and prognosis of ulcerative colitis. Gut 1963;4:299-315.

6. Jain S, Kedia S, Bopanna S, et al. Faecal calprotectin and UCEIS predict short-term outcomes in acute severe colitis: prospective cohort study. J Crohns Colitis 2017;11:1309-1316.

7. Truelove SC, Witts LJ. Cortisone in ulcerative colitis; preliminary report on a therapeutic trial. Br Med J 1954;2:375-378.

8. Magro F, Gionchetti P, Eliakim R, et al. Third European evidence-based consensus on diagnosis and management of ulcerative colitis. Part 1: definitions, diagnosis, extra-intestinal manifestations, pregnancy, cancer surveillance, surgery, and ileo-anal pouch disorders. J Crohns Colitis 2017;11:649-670.

9. Kornbluth A, Sachar DB; Practice Parameters Committee of the American College of Gastroenterology. Ulcerative colitis practice guidelines in adults: American College Of Gastroenterology, Practice Parameters Committee. Am J Gastroenterol 2010;105:501-523.

10. Mowat C, Cole A, Windsor A, et al. Guidelines for the management of inflammatory bowel disease in adults. Gut 2011;60:571607.

11. Brown SR, Haboubi N, Hampton J, George B, Travis SP; ACPGBI. The management of acute severe colitis: ACPGBI position statement. Colorectal Dis 2008;10 Suppl 3:8-29.

12. Nutritional anaemias: report of a WHO scientific group. World Health Organ Tech Rep Ser 1968;405:5-37.

13. Yip R. Final report of the 1995 Viet Nam National Nutrition Anemia and Intestinal Helminth Survey: a recommended plan of action for the control of iron deficiency for Viet Nam. Jakarta, United Nations Children's Fund Indonesia, 1996.

14. Ashavaid TF, Todur SP, Dherai AJ. Establishment of reference intervals in Indian population. Indian J Clin Biochem 2005;20:110-118.
15. Dignass A, Eliakim R, Magro F, et al. Second European evidence-based consensus on the diagnosis and management of ulcerative colitis part 1: definitions and diagnosis. J Crohns Colitis 2012;6:965-990.

16. Silverberg MS, Satsangi J, Ahmad T, et al. Toward an integrated clinical, molecular and serological classification of inflammatory bowel disease: report of a Working Party of the 2005 Montreal World Congress of Gastroenterology. Can J Gastroenterol 2005;19 Suppl A:5A-36A.

17. Travis SP, Schnell D, Krzeski P, et al. Reliability and initial validation of the ulcerative colitis endoscopic index of severity. Gastroenterology 2013;145:987-995.

18. Dignass A, Lindsay JO, Sturm A, et al. Second European evidence-based consensus on the diagnosis and management of ulcerative colitis part 2: current management. J Crohns Colitis 2012;6:991-1030.

19. Travis SP, Farrant JM, Ricketts C, et al. Predicting outcome in severe ulcerative colitis. Gut 1996;38:905-910.

20. Merkley SA, Beaulieu DB, Horst S, et al. Use of intravenous immunoglobulin for patients with inflammatory bowel disease with contraindications or who are unresponsive to conventional treatments. Inflamm Bowel Dis 2015;21:1854-1859.

21. Levine DS, Fischer SH, Christie DL, Haggitt RC, Ochs HD. Intravenous immunoglobulin therapy for active, extensive, and medically refractory idiopathic ulcerative or Crohn's colitis. Am J Gastroenterol 1992;87:91-100.

22. Llaó J, Naves JE, Ruiz-Cerulla A, et al. Improved outcome of acute severe ulcerative colitis while using early predictors of corticosteroid failure and rescue therapies. Dig Liver Dis 2016;48:608-612.

23. Ho GT, Mowat C, Goddard CJ, et al. Predicting the outcome of severe ulcerative colitis: development of a novel risk score to aid early selection of patients for second-line medical therapy or surgery. Aliment Pharmacol Ther 2004;19:1079-1087.

24. Corte C, Fernandopulle N, Catuneanu AM, et al. Association between the ulcerative colitis endoscopic index of severity (UCEIS) and outcomes in acute severe ulcerative colitis. J Crohns Colitis 2015;9:376-381.

25. Pasupula DK, Reddy PS. When is a South Indian really anemic? Indian J Clin Biochem 2014;29:479-484.

26. Collins GS, Reitsma JB, Altman DG, Moons KG. Transparent reporting of a multivariable prediction model for individual prognosis or diagnosis (TRIPOD): the TRIPOD statement. Ann Intern Med 2015;162:55-63. 